\title{
Algunas precisiones sobre la borrosa noción de "Materia" para el diseño interior
}

\section{Pokropek, Jorge; Cravino, Ana [ver currículum del autor, docente de la Facultad de Diseño y Comunicación]}

Resumen: El propósito de este texto es reflexionar sobre las nociones de materialidad y su empleo en la praxis proyectual de los diseñadores de interior, con la intencionalidad de revisar aquellos criterios e instrumentos conceptuales en los que la noción de Materia juega un rol protagónico en dicha praxis. Con este objeto indagaremos sobre las relaciones que se establecen entre Forma y Materia, así como sobre la tensión dialéctica entre espacio configurado y mostración superficial.

Palabras clave: Forma - Materia espacio configurado - espacialidades mostración superficial - textura.

\section{$\left.{ }^{*}\right)$ Arquitecto, UM. Especialista en} Lógica y Técnica de la Forma, FADU-
Cuadernos del Centro de Estudios de Diseño y Comunicación №70

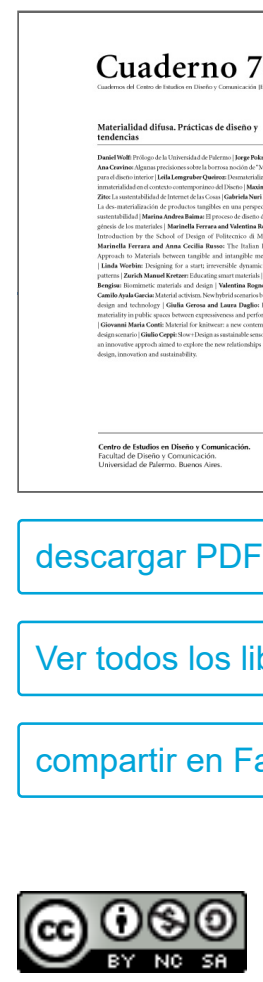

ISSN: 1668-0227

Materialidad difusa.

Prácticas de diseño y

tendencias

Año XIX, Diciembre 2018, Buenos Aires, Argentina | 172 páginas

UBA. Magíster en Lógica y Técnica de la Forma, FADU-UBA. Doctorando, FADU-UBA. Profesor adjunto regular de Morfología General, Morfología 1 y Morfología 2, FADU-UBA. Profesor Adjunto a cargo de Morfología 2, Universidad Nacional de Moreno. Profesor del Doctorado de Diseño, Universidad de Palermo.

$\left.{ }^{(* *}\right)$ Arquitecta, UM. Profesora Superior Universitaria, UM. Magíster en Gestión de Proyectos Educativos, CAECE. Doctora en Arquitectura, FADU-UBA. Investigadora Categorizada del Programa de Incentivos del Ministerio de Educación de la Nación. Investigadora de la UBA y de la Universidad Nacional de la Pampa. Docente de las Universidades de Buenos Aires, ITBA y Palermo.

\section{Introducción}

Este breve escrito pretende establecer algunas reflexiones sobre las nociones de Materia o materialidad y su empleo en la praxis proyectual de los diseñadores de interior, con el fin de alumbrar esa praxis mediante la revisión de aquellos criterios e instrumentos conceptuales en los que la noción de Materia juega un rol 
protagónico. Para ello será menester revisar ciertos conceptos estructurantes de nuestro marco teórico, estipulando los rasgos fundamentales de aquellos términos que los constituyen.

Comencemos por señalar que hablar de diseño interior implica hablar de una práctica proyectual específicamente orientada a la configuración eficaz de entornos habitables o espacialidades arquitectónicas organizadas para estimular, permitir y plenificar el desarrollo de prácticas sociales estructuradas mediante ceremonias y rituales que requieren objetos y espacialidades coherentes con aquellas.

El diseñador de interiores operará proyectualmente dentro y desde la espacialidad arquitectónica intencionadamente estructurada para una o varias prácticas sociales compatibles, tomando esta configuración inicial como "materia prima" de su acción proyectual. Ésta consistirá básicamente en la selección y distribución armónica y coherente de objetos de equipamiento necesario para cada práctica social, así como del adecuamiento del conjunto de elementos o superficies que constituyen la envolvente arquitectónica de la espacialidad envuelta.

Será obvio que para seleccionar y distribuir objetos, así como para intervenir eficazmente en la envolvente, el diseñador deberá saber establecer el grado de coherencia existente entre la envolvente dada y la práctica social a la que está destinada, potenciando o modificando, según el caso, los rasgos que no tiendan a plenificar esa práctica. Para ello deberá ser capaz de comprender los límites y posibilidades de cada tipo espacial arquitectónico, sus lógicas de coherencia y el modo en que estimulan experiencias estéticas, así como los requisitos simbólicos, conductales y emocionales que cada práctica social requiere.

Sinteticemos diciendo, desde este enfoque, que la acción proyectual del diseñador de interiores consiste en producir una "Forma" que organiza la relación armónica entre prácticas sociales, objetos y envolventes; siendo estos elementos conceptuales y físicos la inicial "materia" de trabajo que impone, a su vez, posibilidades y límites.

Una ambientación espacial eficaz y creativa, que tienda a potenciar y mejorar el desarrollo de las conductas humanas mediante el incremento de las experiencias estéticas que esta ambientación estimula, exige comprender profundamente las relaciones existentes entre Forma-Conducta, Forma-Emoción, y FormaSignificado. Es por ello conveniente aquí profundizar y extender los conceptos inherentes a la relación FormaMateria intentando construir una mirada rigurosa que guíe un accionar más rico.

\section{Revisando la relación entre Forma y Materia}

Ya sabemos que las nociones de Forma y Materia constituyen un par dialéctico en el que tiende a originarse toda acción proyectual. Esta tensión dialéctica a la que los antiguos griegos Ilamaron "Hilemorfismo" ha preocupado a generaciones de filósofos y diseñadores. (Ferrater Mora, 1997, pp. 842-844) Veamos, por ejemplo, que Gastón Breyer (1977) (1978) (2003) sostiene que la Forma nace cuando la masa informe, amorfa, de Materia Bruta (la Hyle de los griegos) es organizada por la razón e impuesta como demanda y deseo. Interesa aquí destacar que, para Breyer, siguiendo a Aristóteles, la Materia no tiene "Forma" previa, es "amorfa", "bruta", sin embargo tiene ciertas características o cualidades que estimulan al productor de formas a "organizarla" dándole un principio de orden que permita satisfacer ciertas necesidades o deseos humanos. En 
rigor, la Materia sólo es "amorfa" desde cierto enfoque filosófico generalista, pues en cuanto le descubrimos esos rasgos o cualidades específicas advertimos sus potencialidades y límites configurativos.

Podríamos decir que la Materia es, en síntesis, un conjunto de datos a ser interpretados.

Para Héctor Federico Ras (2006) la noción de Materia se sustituye por la de "energía" al decir que la Forma es la expresión de la energía organizada.

Recordemos que para Aristóteles la noción de Forma representa la esencia del objeto, aquello que hace que una cosa sea lo que es, mientras que la Materia es, simplemente, "aquello de lo que está hecho algo". (Ferrater Mora, 1997, p. 716)

La Forma tiene "Telos", principio de acción o sentido; la Materia conceptualmente pura, no. Pero ya hemos advertido que los diseñadores trabajamos con "materiales" que ya no son materia bruta y pura sino formas primarias, datos, que exigen y estimulan interpretación y organización.

Estos "materiales", al exigir una interpretación correcta sobre sus posibilidades de uso tienden a establecer o estimular criterios valorativos sobre el modo en que se emplean, determinando posiciones conceptuales sobre la percepción correcta o incorrecta, verdadera o falsa, de su expresión. La cultura ha construido dos términos específicos para estas cuestiones: la palabra "Reología" alude al comportamiento "natural" de los materiales, y la palabra "Etopeya" refiere al uso habitual y desempeño atribuido a objetos y materiales. Es desde este enfoque que podemos entender a Louis Kahn (2012, p. 344) cuando preguntaba enigmáticamente cuál era la forma adecuada de la viga de ladrillo y contestaba que la viga de ladrillo "es un arco"..., ya que el ladrillo no puede absorber esfuerzos de flexión.

En un sentido parecido Roberto Doberti (2003) advierte "Las apariencias engañan, las Formas no". Y en esta frase no sólo alude a la noción de forma emparentándola con la de estructura (matriz inmaterial que organiza las Formas. Lo que no cambia en la evolución de ellas), sino que emparenta a la apariencia o mostración superficial de las formas y envolventes, con la capacidad de "mentir", estimulando la búsqueda de la verdad subyacente en la Forma que sostiene la apariencia...

Y aquí interesa como se vinculan las nociones de "verdad" y "belleza" en la expresión de los materiales, influyendo durante años en los criterios de diseño de la habitación humana. Recordemos, por ejemplo, como en el siglo XIX, a tono con el espíritu moralista victoriano, John Ruskin (1964, p. 62) formula entre las Siete lámparas de la arquitectura la "Lámpara de la verdad" planteando una nueva relación entre Forma y Materia, cuestionando como "mentiras" arquitectónicas: "la sugerencia de una forma de estructura o soporte que no es la verdadera", tanto como "las superficies pintadas imitando algún otro material distinto al que es en realidad", así como "Il uso de ornamentos de cualquier clase, hechos con molde o mecánicamente". Ruskin cuestionaba los efectos de la Revolución Industrial en la arquitectura y el diseño. Para él una obra genuina debería manifestar la armonía entre las leyes "naturales" de los materiales utilizados y el empleo de los mismos de manera artesanal; es por eso que exige "verdad" en la construcción, marcando su preferencia por materiales como madera y piedra, y sentenciando que "la verdadera arquitectura no admite el hierro como material constructivo"... 
Pensamiento similar expresa hacia 1925 Egon Friedell (1931, pp. 299-300) quien cuestiona la artificiosidad de los interiores de la alta burguesía en Viena:

Las suyas no eran viviendas, sino casas de empeño y tiendas de curiosidades... Tenían manía por artículos de decoración enteramente desprovistos de significación..., manía por superficies de raso: por la seda, el raso y el cuero lustrado; por los marcos dorados, los estucos dorados y los bordes dorados; por el carey, el marfil y la madreperla, así como por artículos de decoración enteramente desprovistos de significación... ( ) En conexión con esto, había una clara ausencia de todo cuanto pudiese aludir a alguna utilidad o función; todo estaba allí para ser visto.

Señalando críticamente, al igual que Ruskin, que en aquellos interiores "Todos los materiales empleados intentaban aparentar más de lo que eran. Máscaras de hojalata pintadas de blanco pasaban por marfil; el cartón piedra, por palo de rosa; el yeso, por fúlgido alabastro; el vidrio, por ónice suntuoso..."1

Durante la naciente modernidad, en la Escuela de la Bauhaus los problemas emergentes de la relación entre Forma y Materia alcanzaron un papel protagónico en torno a la definición de los diseños. Sin embargo, a partir de 1927 cuando asumiera la dirección de la institución Hannes Meyer el compromiso político y social del diseñador sería prioritario, debiendo servir a satisfacer las necesidades de los sectores más vulnerables, evitando las tentaciones formalistas y esteticistas que habían guiado el quehacer de otros movimientos como el Arts and Craft y la Deutsche Werkbund, de manera tal, que la relación Forma-Materia debería ser mediatizada por la Utilidad, lo que no era otra cosa que volver a la clásica triada vitruviana. Es por ello que Luis Arenas (2008, p. 10) sostiene que en ese período de la Bauhaus "Tanto un edificio como una modesta silla era el producto de una planificación sistemática que debía estar acorde con las exigencias del material y con las necesidades del usuario". En 1927, siguiendo la impronta marcada por Meyer, Mies van der Rohe (1927, p. 59) señalaba que no existían problemas de forma, sólo problemas de construcción...2

Es obvio que con esto Mies (1923, p. 1) quería romper el desprecio academicista por los problemas tecnológicos, pero menos evidente es el vínculo profundo que durante la dé- cada del veinte y comienzos del treinta se estableció entre el Círculo de Viena y la Bauhaus. De tal modo que el aparente rechazo explicitado hacia la Forma no es otro que la oposición a la metafísica que sostiene el positivismo lógico. No es casual entonces que el Manifiesto del Círculo de Viena concluyera con:

Experimentamos cómo el espíritu de la concepción científica del mundo penetra en creciente medida en las formas de vida pública y privada, en la enseñanza, en la educación, en la arquitectura, y ayuda a guiar la estructuración de la vida social y económica de acuerdo con principios racionales. La concepción científica del mundo sirve a la vida y la vida la acoge. (Hahn-Neurath-Carnap, 2002, p. 124)

Al mismo tiempo que el ubicuo Mies afirmaba de manera similar "una forma real presupone una vida real. ( ) La vida es para nosotros el factor decisivo". En ese contexto es que la conferencia que dictara en la Bauhaus en 1929 Rudolf Carnap, miembro del Círculo de Viena, se llamaría "Ciencia y vida" mientras que simultáneamente Hannes Meyer definiría al acto de construir como la organización de los procesos vitales. Es interesante notar que Kenneth Frampton (1987, p. 9) destaca la "desmaterialización materializada" de la arquitectura de Mies, ya que éste "veía el material como una substancia en sentido fenoménico, esto es, lo consideraba un material 
nuevo que había que abordar mediante la inversión de los modos tradicionales de la concepción y la percepción arquitectónica".

Durante la vigencia del Movimiento Moderno, a pesar de numerosos dichos acerca de la importancia del empleo de nuevos materiales y tecnologías, así como de la industrialización de la construcción, el nuevo par, celebrado por el funcionalismo, estableció la potente relación entre Forma y Función. Vale en este sentido mencionar la investigación realizada oportunamente por Juan Pablo Bonta (1977, pp. 220-232) sobre la inasible materialidad constructiva del Pabellón Alemán realizado por Mies en Barcelona...

Recordemos asimismo dos definiciones: Alison y Peter Smithson (1965, p. 590) estipulaban que:

Esencialmente una arquitectura moderna fue (a) Cúbica, o parecía tallada desde cubos. (b) Organizada geométricamente y muy abstracta en su interpretación de las actividades humanas. (c) Algo completo, en sí mismo. (d) Colocada, no enraizada a su sitio. (e) Normalmente blanca y de colores fuertes, o hecha de materiales brillantes. (f) Los materiales naturales cuando eran usados aparecían como substitutos de materiales artificiales todavía no inventados.

Coincidiendo en este punto con las consideraciones que Frampton formularía sobre Mies Mientras que Montaner (1993) dice que:

Tres son los principios formales básicos de esta arquitectura: la arquitectura como volumen, como juego dinámico de planos más que como masa; el predominio de la regularidad en la composición, sustituyendo a la simetría axial académica; y la ausencia de decoración añadida que surge de la perfección técnica y expresividad del edificio a partir del detalle arquitectónico y constructivo.

En estas dos caracterizaciones la materialidad se expresa como un aspecto menor del diseño, quedando, de esta manera, el material constreñido a la tecnología empleada, con la implícita condición que la categoría textural del material -ligada a las técnicas artesanales superadas- desapareciera en pos de alcanzar una máxima abstracción geométrica. Este propósito manifestaba la paradoja tecnológica de la modernidad: alcanzar una materialidad inmaterial o como diría Frampton "desmaterializada".

En su serie de libros sobre Materiales de Proyecto, Helio Piñón (2005, p. 5) sostiene en el prefacio que:

Al situar el proyecto de arquitectura en el ámbito de las ideas, e identificarlas con la manifestación de meras intenciones, se desvanece su condición esencialmente formal -estructurante, ordenadora-, lo que provoca el eclipse de la noción de materia: en efecto, la consideración del material constructivo -elementos físicos con que se afronta la construcción- es obviada, en general, por considerarla un momento secundario respecto de "la idea", de modo que a menudo ésta se describe sin ninguna alusión a la materialidad del objeto.

Esta devaluación de la materia, en su sentido más cotidiano -el de material de construcción- que reaparece de una manera nueva en el siglo XXI, se diferencia de aquel otro desprecio de lo constructivo que tuvieran los arquitectos a fines del novecento que implicó la diferenciación entre el oficio del ingeniero orientado a operar con la prosaica materia y el del arquitecto que se definía a la manera de Alberti como "decorador de fachadas", como un manipulador de la etérea belleza. En este tiempo presente que vivimos, los materiales no son ya un obstáculo prosaico para la idea sublime: la forma puede prácticamente materializarse de muchas maneras... 
Observemos por cierto que Piñón (2005, p. 5) le da un nuevo enfoque a la noción de "Materia", y esto va entrañar:

Hablar de material de proyecto, es decir, aquellos elementos, criterios, o soluciones, pertenecientes a la experiencia propia o ajena, que constituyen la materia prima del proyecto a la que el sentido del orden de quien proyecta conseguirá dotar de estructura formal.

Esta definición abre el juego hacia un número importante de "materiales", es decir todo aquello que tendrá en cuenta el diseñador en el momento de iniciar su proceso proyectual, desde los requerimientos, recursos y condicionantes que se explicitan en esta instancia germinal hasta aquellos otros, no tan obvios ni conscientes que constituyen la estructura conceptual, los referentes, los valores, la sensibilidad o las herramientas proyectuales que posee el propio diseñador.

3. Los materiales en el Diseño de Interiores: lo espacial y lo textural

Cuando hablamos de Diseño de Interiores debemos diferenciar entre el espacio configurado y los materiales configurantes. Sin embargo estos configurantes, al perder su papel de estructura soporte y abrigo (dominados por la arquitectura) quedarán limitados a su mostración superficial o textura, textura que debe ser reconquistada en todas sus cualidades. Respecto al hueco configurado debemos recordar los trabajos iniciales de Arnheim (2001) y Ras (1989) (1999) (2006), así como la taxonomía elaborada por Pokropek (2015) donde se redefinen las nociones de patio, claustro, ambulatorio, enclave, recinto adscripto y recinto adyacente, así como las espacialidades ambiguas como la partición de un continuo y la fusión en continuo, incluyendo también los intersticios espaciales entre figuras plásticas o volúmenes macizos...

En función de la condición material o virtual, es decir, llena o vacía, de las figuras protagónicas, podremos establecer tres grandes grupos o "estados" de la espacialidad organizados categorialmente, es decir, sobre un eje que vincula nociones opuestas en cada extremo y establece un territorio intermedio de ambigüedad o equilibrio.

Desde este enfoque clásico tendremos en un extremo del modelo polar al conjunto de las organizaciones formales cuyas entidades o figuras protagónicas pueden describirse como recintuales, vacías o virtuales por tratarse esencialmente de lo que solemos denominar "Recintos" o "Habitaciones". Podemos advertir que al experimentar estas espacialidades el sujeto se percibe "dentro" de una burbuja o membrana virtual que, merced a sus proporciones es perceptualmente más nítida o pregnante que el conjunto de entidades materiales que la configuran. El universo formal de las figuras huecas o "recintuales", es vasto y merece oportunas profundizaciones futuras. (Pokropek, 2015)

En el extremo opuesto del eje categórico encontramos las espacialidades compuestas por entidades o figuras protagónicas factibles de percibirse como "Ilenas", macizas o "plásticas". Tradicionalmente llamamos a estas organizaciones formales como "sostén de figuras plásticas" por estar "sostenidas" o "consistir" en conjuntos de volúmenes perceptualmente llenos o macizos, oponiéndole los sistemas formales definibles como "sostén de figuras recintuales". El lenguaje es estricto al respecto: se está "dentro" de un recinto o se está "entre volúmenes macizos" o "en" un territorio intersticial. 
Siguiendo a Ras (2006) recordemos ahora que la noción de "Intersticio" alude a una condición espacial carente de la suficiente fortaleza formal o aptitud figurativa que impide leerla como figura protagónica. En el caso de las espacialidades del tipo "Sostén de figuras Plásticas" el territorio intersticial constituye el necesario y fundamental "fondo" donde se recortan o leen las "figuras". Obvio es señalar que intersticios espaciales puede haber tanto entre figuras plásticas como entre figuras recintuales. Su proliferación y protagonismo formal en algunas espacialidades pueden llevarnos a clasificarlas, oportunamente, como "fusión en continuo".

Reinterpretando la noción de "ámbito" empleada por Ras, diremos que, para nosotros, "Fusión en continuo" reemplaza este término ambiguo, e involucra al conjunto de espacialidades cuya organización formal presenta un equilibrio dinámico, homogeneizador entre las diversas partes del sistema que dificulta percibirlas como individuos para subsumirlas en una sensación de globalidad e ilimitación donde radica la coherencia del sistema. Según Ras, el tipo configurativo "Ámbito" (Fusión en continuo) tiene su principio de consistencia en percibir precisamente como protagónica la relación equilibrada entre las diversas partes, pudiendo ser éstas: Plásticas, Recintuales o Mixtas. Este equilibrio dinámico depende fundamentalmente de la distribución relativamente homogénea de las partes del sistema y de su capacidad de subordinación figurativa en función del todo merced a una "fusión textural" que dificulta segregar cada entidad del conjunto.

Para Ras las tramas espaciales, cuando se expresan no como organizadoras de una figura sino como protagónicas participantes de la organización formal, tienden a constituir un ámbito (fusión en continuo en nuestra nomenclatura). La interioridad selvática es, asimismo, otro ejemplo posible donde la noción de textura vegetal se impone a la percepción de cada planta. Desde ese mismo enfoque un conjunto ilimitado de recintos transparentes tiende a percibirse como fusión en continuo. Actualmente se están explorando organizaciones formales a partir del plegado de una entidad laminar protagónica (Toyo Ito, Ben van Berkel, etc.) la cual, en función de sus desplazamientos espaciales tiende simultáneamente a fragmentar y vincular inestables recortes espaciales que tienden, según el caso, a proponerse como vacíos figurativos. Advirtamos que una organización espacial así configurada deberá clasificarse como fusión en continuo mientras se lea como figura protagónica del sistema a la relación dialéctica entre los pliegues de la lámina material y sus intersticios espaciales o vacíos no figurativos. No sucedería lo mismo si, manteniendo un equilibrio dinámico entre llenos y vacíos, los pliegues laminares tendieran a configurar vacíos figurativos. En este caso estaríamos en presencia del cuarto tipo configurativo espacial básico nominado tradicionalmente por Ras como "Partición de un continuo".

Recordamos que, según Ras:

Se entiende por "partición de un continuo" al sistema formal en el cual la fortaleza figural de los elementos plásticos que lo integran se equilibra con la de las formas huecas que ellas proponen. Es un caso de ambigüedad en la categoría de consistencia.

Observemos que la experiencia espacial que el sujeto experimenta al recorrer una organización formal del tipo "Partición de un continuo" consiste en advertir la tensión espacial generada en la insatisfacción configurativa de los vacíos con vocación recintual merced a la estratégica disposición y tamaño de placas o láminas materiales.

Clasificar y nombrar "Partición de un continuo" a este particular sistema formal ubicado en la zona de ambigüedad entre las espacialidades recintuales y plásticas, obedece al deseo de expresar lo más diáfanamente posible la compleja pero no inefable experiencia mental de percibir simultáneamente un continuo espacial a 
punto de fragmentarse en sucesivos recintos, o un débil recinto a punto de diluirse o fluir en un continuo espacial... Experiencia frecuente en museos o galerías de arte.

En síntesis, habiéndonos "metido" en la organización formal de una espacialidad interior merced a que ésta es penetrable y recorrible, advertiremos que las entidades o "figuras", materiales ("llenas") o virtuales ("vacías"), que constituyen la organización formal, poseen características específicas de ubicación que determinan la estructura del sistema, y características específicas de mostración o apariencia que determinan su textura.

Arnheim (2001) señala que:

El diseño, naturalmente, no es ni más ni menos que la creación de las formas tangibles y visibles de un edificio. ¿Cómo, entonces, el diseño puede llegar a ser considerado como algo de lo que se puede prescindir? ( ) ¿O esta aversión es una protesta contra una cruzada más reciente de desnudez, que esconde la variedad de los impulsos humanos en una geometría pura pero a menudo vacía? Sea cual fuere la causa, cualquier intento de evitar la responsabilidad última del arquitecto debe ser vano. Se puede desdeñar la forma de un objeto, pero no es posible prescindir de ella.

Esta sentencia de Arnheim pareciera ser una respuesta a aquel ambiguo Mies de 1927. La geometría pura no elimina al diseño, la racionalización no reemplaza en modo alguno a la experiencia perceptual de un sujeto que interactúa en, dentro o entre estas espacialidades. Sin embargo la noción de tangibilidad termina cruzada por lo perceptual, de tal modo que real y virtual muchas veces se cruzan y se desdibujan...

En este sentido recordemos que las estructuras pueden ser explícitas o implícitas según la materialidad o inmaterialidad de las entidades que la forman. Para su percepción sensible requieren de una materialidad visible que expresa ciertas características formales. Ya dijimos que esta expresión de la materialidad sensiblemente percibida recibe el nombre de textura o mostración superficial. Ras (2006, p. 24) dice que se puede definir la textura como la modalidad según la cual se pone de manifiesto la superficie o volumen de un objeto, "in abstracto" de él. Ras también propone un listado de categorías formales texturales cuyo empleo frecuente permite establecer patrones en las relaciones forma-conducta, forma-emoción.

Los pares categóricos texturales más empleados en el análisis de las espacialidades así como en su configuración intencionada son: homogéneo-heterogéneo, denso-diáfano, transparente-opaco, esquemáticofarragoso, céldico-ambitual, luminoso-oscuro, brillosomate, permeable-impermeable, rugoso-liso, áspero-suave, cálido-frío, artificial-natural, blando-duro, etc. Categorías que podrían ser expresadas con diferentes materiales físicos y cuya concreción dependerá de aspectos perceptuales o fenoménicos y de la intencionalidad estética propuesta. Vale en este sentido mencionar el clásico análisis de Sven Hesselgren (1973, p. 323) donde vincula los aspectos ópticos con los táctiles en los tradicionales materiales de construcción: "el hecho de que la percepción táctil da expresión al material no parece resultar de la experiencia individual ni de asociaciones privadas, sino que parece ser, evidentemente, un fenómeno humano espontáneo y común (intersubjetivo)". Es interesante además notar que estas "transferencias metafóricas" entre sentidos habían sido ya reconocidas por Nelson Goodman (1990, p. 25) cuando, por ejemplo, se califican categorías visuales con predicados atribuibles a lo auditivo o táctil como es el caso de estridente y atenuado, o suave y áspero.... 
Esta convergencia fenomenológica y sensorial puede apreciarse en la caracterización que realiza Simon Unwin (2010, p. 215) de los Baños Termales de Vals, obra de Peter Zumthor donde sostiene que "se trata de un edificio que ofrece para todos los cinco sentidos, la vista, el tacto, el oído, el olfato y gusto, pero promete otras sensaciones también..."

Señalemos que los listados posibles de características texturales o estructurales pueden extenderse según la conveniencia del diseñador, quien podrá hacer uso protagónico de categorías formales aquí no enumeradas. El mismo Peter Zumthor (2006, p. 22) rescata lo que el denomina la "consonancia de los materiales", ya que éstos tienen miles de posibilidades de empleo, pero no cualesquiera, dependiendo su uso de la sensibilidad del proyectista, destacando asimismo cómo estos materiales pudieran reflejar la luz y el sonido, lo cual redunda obviamente en la experiencia espacial. Parecida conclusión formula Christopher Williams (1984) quien sentencia que:

Todos los materiales poseen sus características idiomáticas. El idioma de ese material es una exigencia formulada a su usuario, para que comprenda su identidad personal y su significado, sus fuerzas y sus debilidades, su estructura, sus formas más cómodas, su mejor uso.

Es por ello que Luis Moreno Mansilla (2005, p. 146) pareciera concluir diciendo que: "porque la materia no cambia cuando la miramos, pero nuestros ojos sí. El espacio de la arquitectura es entonces el instante en que se desdobla el perfil de las cosas, de la materia." No podemos en este punto eludir tanto las exploraciones actuales de Herzog \& Meuron en torno a lo textural, de Toyo Ito, Kazuyo Sejima y Shigeru Ban sobre la porosidad de los elementos configurantes, como aquellas otras iniciadas entre el 50 y 60 por Franco Albini, Carlo Scarpa y Mario Ridolfi que implicaron no sólo una oposición a la abstracción moderna sino también una crítica al brutalismo entonces vigente, tarea que se fundamentó a partir de la consideración que "el ejercicio de análisis y de explicitación del material provisto por las leyes de construcción y conformación del objetivo arquitectónico era la substancia principal...", lo cual había significado por un lado tanto la "negación del valor de la construcción como material portante..." como "un renacimiento de interés por la decoración, o mejor por el ornato (según la distinción que Rogers hacía de estos dos términos)”. (Gregotti, 1985, p. 2)

Vale también en este sentido observar obras que enfatizan los aspectos texturales de los configurantes como los interiores del nuevo hotel en Atenas de los hermanos Campana, el Museo Groninger de Alessandro Mendini, el restaurante Switch de Dubai de Karim Rashid o el Hotel Mandarin Oriental de Barcelona de Patricia Urquiola, texturas que contribuyen a la ambitualización espacial, e incluso a la propia desmaterialización de los configurantes...

\section{Conclusiones provisorias}

Esta breve reflexión sobre la relación entre la noción de Materia y la praxis proyectual de los diseñadores de interior debe, necesariamente, intentar ofrecer una síntesis que guíe esa praxis.

Digamos entonces que, como hemos señalado, la noción de materia admite desdoblarse en dos grandes grupos conceptuales básicos. 
En un grupo ubicaremos aquellas materias o materiales de carácter abstracto, intangible o simbólico al que Pinón conceptualizara como "Materiales de Proyecto", es decir al conjunto de ideas, preexistencias proyectuales, y requisitos específicos de las prácticas sociales. Este conjunto de datos previos, de interpretación inevitable y creativa, orientará la estrategia proyectual, instrumentada mediante operaciones de diseño sobre materiales tangibles, concretos, con estructura y textura dada, con historia propia y significados intrínsecos y atribuidos, así como respuestas percetuales específicas que tienden a estimular emociones y conductas prefijadas en el receptor habitante mediante códigos interpretativos de origen filogenético y ontogenético3 .

Profundicemos en estos últimos dichos por su importancia para el saber hacer proyectual. Ya dijimos que el receptor-habitante al percibir el conjunto de elementos que configuran un entorno habitable intencionado para satisfacer una práctica social experimenta diversos estímulos traducidos en sensaciones e interpretados simbólicamente que pueden organizarse para producir una experiencia estética cuando el principio de orden que los guía produce un efecto de sentido que trasciende las funciones utilitarias para alcanzar la función estética.

Interesa aquí hacer hincapié en la importancia de la relación estímulo-respuesta. Hemos mencionado que el receptor-habitante experimenta su entorno físico mediante un mecanismo mental que los psicólogos de la Gestalt llaman "mecanismo de transformaciones propioceptivas". Este mecanismo establece que todas las percepciones visuales tienden inevitablemente, en traducirse experiencialmente como percepciones olfativas, gustativas, auditivas y hápticas. Asimismo estas percepciones encadenadas armónicamente determinan interpretaciones o lecturas de significados intrínsecos a la organización formal y a su mostración textural. Hablamos entonces de calidez o frialdad, solemnidad o espontaneidad según el modo en que el entorno ha sido organizado.

Desde este enfoque será fundamental que el diseñador de interiores sepa establecer mediante la sabia selección de texturas, organizaciones espaciales y objetos aquellas cadenas armónicas perceptuales que tiendan a estimular intencionadamente la adecuada relación entre emociones, conductas y significados.

El hábil manejo de categorías sintácticas enhebradas armónicamente en función de una intención estética constituye el núcleo del saber hacer proyectual.

La distancia entre espacialidades que estimulen experiencias opuestas, tales como la espiritualización anímica versus la sensualidad o el hedonismo, dependen, insistimos, de la selección de cadenas armónicas de polos que guíen la selección y el diseño de las texturas del entorno. La interpretación de espacios espiritualizados, propicios para prácticas solemnes y simbólicamente trascendentes, suele organizarse dentro del borroso concepto de "minimalismo", un sistema formal definido, esquemático, céldico, frío, homogéneo, diáfano, con iluminación difusa que tiende a interpretarse como ascético, sobrio, esencial, "verdadero", y por lo tanto, espiritualmente profundo. Propicio para el pensar pero no para el amor y la gula. El goce erótico convoca, en cambio, lo indefinido, farragoso, ambitual, cálido, heterogéneo, con iluminación escasa o sectorialmente focalizada y, atmósfera densa. Estas categorías tienden a leerse como protagónicas de una espacialidad rica, exuberante, amable por blanda y versátil, propicia para reuniones sociales distendidas y alegres.

Las nociones de lujo, elegancia, juventud, libertad, alegría o tristeza, se "materializan" mediante texturas y lógicas organizativas. Sobre ellas y desde ellas debe trabajar el diseñador de interiores, respetando en principio 
la lógica proyectual propuesta inicialmente por la espacialidad arquitectónica dada, y por la adecuación a la práctica social protagónica. Por ahora, nada más

Notas

1. Friedell, Egon (1932). A Cultural History of the Modern Age,, Alfred Knopf, Nueva York, Pág. 299-300. https://monoskop.org/images/a/ae/Friedell_Egon_A_Cultural_History_of_the_Modern_Age_Vol_3.pdf

Citado también por (Janik, - Toulmin, 1998, p. 121)

Parecido "horror vacuil" se presenta en la crónica del casamiento de Carlos María de Alvear con María Mercedes Elortondo según una nota publicada en el diario El Nacional de mayo de 1882 en el se describe el Palacio de la familia.

2. Citado también en (Banham,1985, p. 271) (Drexler, 1961, p. 7) (Neumeyer, 1995, pp. 393-394).

3. Recordar la función primaria y secundaria de Umberto Eco...

Bibliografía

Arenas, L. (2008). La casa como gesto. La arquitectura en Wittgenstein y el neopositivismo vienés. Disponible en http://www.unizar.es/seminario/archivos/luis_arenas_la_casa_como_gesto.pdf

Arnheim, R. (2001). La forma visual de la arquitectura. Barcelona: Editorial Gustavo Gili.

Banham, R. (1985). Teoría y diseño en la primera hora de la máquina. Barcelona: Paidós.

Bonta, J. P. (1977). Sistemas de significación en arquitectura. Barcelona: Editorial Gustavo Gili.

Breyer, G. (1978). “La heurística del diseño" en Revista Summa № 131, Buenos Aires, diciembre de 1978.

Breyer, G. (1977). “Morfología y heurística” en Sumario № 9/10, Buenos Aires, 1977.

Breyer, G. (2003) ."Introducción” en Giordano, D.; Wainhaus, H.; Pescio, S.; Pereyra, C. y Frigerio, M. C. (2003). Cinco notas sobre Heurística del Diseño, FADU/Cuadernos de Cátedra, Buenos Aires.

Doberti, R. (2008). Espacialidades. Buenos Aires: Ediciones Infinito.

Drexler, A. (1961). Mies Van der Rohe. Barcelona: Editorial Bruguera.

Ferrater Mora, J. (1997). Diccionario de Filosofía, Tomo I y Tomo II, Sudamericana, Buenos Aires.

Frampton, K. (1987). "Modernidad y tradición en la obra de Mies van der Rohe" en Summarios №. 114, 1987

Friedell, E. (1932). A Cultural History of the Modern Age, Alfred Knopf, Nueva York en

https://monoskop.org/images/a/ae/Friedell_Egon_A_Cultural_History_of_the_Modern_Age_Vol_3.pdf 
Gregotti, V. (1985). “El ejercicio del detalle" en Summarios No 93 "Dios está en los detalles", septiembre de 1985.

Kahn, L. (2012). “Amo los inicios” en Hereu, P.; Montaner, J. M. y Oliveras, J. (ed.) (2012) Textos de arquitectura de la modernidad. Barcelona Editorial: Nerea.

Goodman, N. (1990). Maneras de hacer mundos. Madrid: Visor.

Janik, A. y Toulmin, S. (1998). La Viena de Wittgenstein. Madrid: Taurus.

Hahn, H.; Neurath, O. y Carnap, R. (2002). "La concepción científica del mundo: el Círculo de Viena” en REDES Revista de Estudios sobre la Ciencia y la Tecnología Vol. 9, № 18, junio de 2002, Buenos Aires.

Mies van der Rohe, L. (1923). "Bauen” publicada en la revista G №2, septiembre de 1923.

Mies van der Rohe, L. (1927). "Ubre die Form in der Architektur”, publicada en la revista Die Form № 2. 1927.

Montaner, J. M. (1993). Después del Movimiento Moderno - Arquitectura de la segunda mitad del siglo XX Arquitectura ConTextos. Barcelona: Editorial Gustavo Gili.

Moreno Mansilla, L. (2005). "Sobre la confianza en la materia” en Moreno Mansilla, L.; Rojo, L. y Tuñón, E. (2005). Escritos Circenses. Barcelona: Editorial Gustavo Gili.

Neumeyer, F. (1995). Mies van der Rohe, la palabra sin artificio. Madrid: El Croquis Editorial.

Pokropek, J. (2015). La Espacialidad Arquitectónica. Buenos Aires: Nobuko.

Ras, H. F. (1989). Ensayo. Memorias sobre Morfología, Conducta y Estética. Buenos Aires: Serie Ediciones Previas - FADU- UBA.

Ras, H. F. (1999). El entorno y su imagen. Buenos Aires: Editorial Laf.

Ras, H. F. (2006). Las Expresiones de la Arquitectura. Buenos Aires: FADAU-UM.

Ruskin, J. (1964). Las siete lámparas de la arquitectura. Pamplona: Aguilar.

Smithson, A. y Smithson, P. (1965). "El período Heroico de la arquitectura moderna" en Architectural Design № 12, Diciembre 1965.

Unwin, S. (2010). "Thermal Baths, Vals" en Twenty Buildings Every Achitect Should Understand. Routledge, Taylor \& Francis Group. London - New York.

Williams, C. (1984). Los orígenes de la forma. Barcelona: Ed. Gustavo Gili.

Zumthor, P. (2006). Atmósferas. Barcelona: Ed. Gustavo Gili. 
Abstract: This paper reflects on the notions of materiality and its use in the design praxis of interior designers. The purpose is to review those criteria and conceptual tools in which the notion of Matter has a leading role. With this object we will inquire about the relations that are established between Form and Matter, as well as about the dialectical tension between configured space and superficial display.

Key words: Form - Matter - Configured space - specialities - Superficial display - Texture

Resumo: este artigo apresenta uma reflexão sobre as noções de materialidade e seu uso na prática Projetual dos designers de interior, com a intenção de revisar critérios e instrumentos conceptuais onde o conceito de matéria tem um papel primordial nessa prática. Com esse objetivo, se indagará nas relações que se estabelecem entre Forma e Matéria, assim como a tensão dialética entre espaço configurado e expressão superficial.

Palavras chave: forma - matéria - espaço configurado - espacialidades - expressão superficial - textura.

Algunas precisiones sobre la borrosa noción de "Materia" para el diseño interior fue publicado de la página 15 a página27 en Cuadernos del Centro de Estudios de Diseño y Comunicación N70 